LAWRENCE LIVERMORE N A T IO N A L LABORATORY

Kinetics of HMX and CP Decomposition and Their Extrapolation for Lifetime Assessment

Alan K. Burnham, Randall K. Weese, William J. Andrzejewski

December 6, 2004 
This document was prepared as an account of work sponsored by an agency of the United States Government. Neither the United States Government nor the University of California nor any of their employees, makes any warranty, express or implied, or assumes any legal liability or responsibility for the accuracy, completeness, or usefulness of any information, apparatus, product, or process disclosed, or represents that its use would not infringe privately owned rights. Reference herein to any specific commercial product, process, or service by trade name, trademark, manufacturer, or otherwise, does not necessarily constitute or imply its endorsement, recommendation, or favoring by the United States Government or the University of California. The views and opinions of authors expressed herein do not necessarily state or reflect those of the United States Government or the University of California, and shall not be used for advertising or product endorsement purposes.

This work was performed under the auspices of the U.S. Department of Energy by University of California, Lawrence Livermore National Laboratory under Contract W-7405-Eng-48. 


\title{
Kinetics of HMX and CP Decomposition and Their Extrapolation for Lifetime Assessment
}

\author{
Alan K. Burnham, ${ }^{1}$ Randall K. Weese, ${ }^{1}$ and William J. Andrzejewski ${ }^{2}$ \\ ${ }^{1}$ Lawrence Livermore National Laboratory, Livermore, CA 94550 \\ ${ }^{2}$ Sandia National Laboratories, Albuquerque, NM 87185
}

\begin{abstract}
Decomposition kinetics are determined for HMX (nitramine octahydro-1,3,5,7tetranitro-1,3,5,7-tetrazocine) and CP (2-(5-cyanotetrazalato) pentaammine cobalt (III) perchlorate) separately and together. For high levels of thermal stress, the two materials decompose faster as a mixture than individually. This effect is observed both in hightemperature thermal analysis experiments and in long-term thermal aging experiments. An Arrhenius plot of the $10 \%$ level of HMX decomposition by itself from a diverse set of experiments is linear from 120 to $260{ }^{\circ} \mathrm{C}$, with an apparent activation energy of 165 $\mathrm{kJ} / \mathrm{mol}$. Similar but less extensive thermal analysis data for the mixture suggests a slightly lower activation energy for the mixture, and an analogous extrapolation is consistent with the amount of gas observed in the long-term detonator aging experiments, which is about 30 times greater than expected from HMX by itself for 50 months at 100 ${ }^{\circ} \mathrm{C}$. Even with this acceleration, however, it would take 10,000 years to achieve $10 \%$ decomposition at $\sim 30{ }^{\circ} \mathrm{C}$. Correspondingly, negligible decomposition is predicted by this kinetic model for a few decades aging at temperatures slightly above ambient. This prediction is consistent with additional sealed-tube aging experiments at $100-120{ }^{\circ} \mathrm{C}$, which are estimated to have an effective thermal dose greater than that from decades of exposure to temperatures slightly above ambient.
\end{abstract}

\section{INTRODUCTION}

Accelerated aging tests play an important role in assessing the lifetime of manufactured products. There are two basic approaches to lifetime qualification. One tests a product to failure over range of accelerated conditions to calibrate a model, which is then used to calculate the failure time for conditions of use. A second approach is to test a component to a lifetime-equivalent dose (thermal or radiation) to see if it still functions to specification. Both methods have their advantages and limitations.

A disadvantage of the second method is that one does not know how close one is to incipient failure. This limitation can be mitigated by testing to some higher level of dose as a safety margin, but having a predictive model of failure via the first approach provides an additional measure of confidence. Even so, proper calibration of a failure model is non-trivial, and the extrapolated failure predictions are only as good as the model itself and the quality of the calibration.

This report outlines results for predicting the potential failure point of a system involving a mixture of two energetic materials, HMX (nitramine octahydro-1,3,5,7tetranitro-1,3,5,7-tetrazocine) and CP (2-(5-cyanotetrazalato) pentaammine cobalt (III) perchlorate). Global chemical kinetic models for the two materials individually and as a mixture are developed and calibrated from a variety of experiments. These include 
traditional thermal analysis experiments run on time scales from hours to a couple days, detonator aging experiments with exposures up to 50 months, and sealed-tube aging experiments for up to 5 years.

Even though HMX and CP clearly interact with each other under severe thermal exposure conditions, the mixture is still quite stable thermally when compared to most energetic materials. Our conclusion is that sealed mixtures of $\mathrm{HMX}$ and $\mathrm{CP}$ will not have significant deterioration over a few decades at temperatures $<40{ }^{\circ} \mathrm{C}$.

\section{EXPERIMENTAL METHODS}

\section{A. Samples}

HMX (Lot \# 81H030-033) used in the thermal analysis experiments was manufactured by Holston Defense Corporation for Lawrence Livermore National Laboratory using the Bachmann synthesis process and was determined to be $>99.90 \%$ pure as analyzed by HPLC for RDX impurities. Particle-size analysis indicated that $>90 \%$ of the material was between 30 and $500 \mu \mathrm{m}$ in diameter. CP was manufactured by Pacific Scientific of Chandler, AZ. Lot \#82936 was used for the thermal analysis experiments, and Lot \# 81931 was used for the sealed-tube experiments.

\section{B. Thermal Analysis}

A Differential Scanning Calorimeter (DSC), TA Instruments Model 2920, and its associated software, Universal Analysis, were used to monitor the rate of reaction of HMX-CP mixtures. These experiments used hermetically sealed pans. Sample sizes were typically $0.45 \mathrm{mg}$, and heating rates were $0.1,0.35$, and $1.0^{\circ} \mathrm{C} / \mathrm{min}$.

Weight loss measurements of HMX, CP, and various mixtures thereof were carried out using a TA Instruments Simultaneous Differential Thermogravimetric Analyzer (SDT), model 2960. The SDT instrument is capable of performing both thermogravimetric analysis (TGA) and differential thermal analysis (DTA) at the same time. These experiments used TA open aluminum pans. From 0.4 to $3 \mathrm{mg}$ of total material was used, but never more than $1.5 \mathrm{mg}$ of energetic components (HMX $+\mathrm{CP}$ ). Degradation was carried out under nitrogen carrier gas at a flow rate of $100 \mathrm{~cm}^{3} / \mathrm{min}$. Isothermal experiments were conducted between 190 to $250{ }^{\circ} \mathrm{C}$.

\section{Sandia Accelerated Aging Tests}

A group of detonators containing $\mathrm{CP}$ and HMX were aged isothermally in ovens at 50,75 , and $100{ }^{\circ} \mathrm{C}$ for periods of 24 and 50 months. Three to five detonators were exposed at each condition. Two detonators were analyzed at the start for a baseline. Five detonators were held at room temperature for 50 months and used as controls. Independently, a set of sealed tubes containing only HMX were heated for up to 5 years at temperatures of $60,80,100$, and $120{ }^{\circ} \mathrm{C}$, with evolved gases analyzed at six months intervals. A subsequent set of sealed-tube experiments exposed $100 \mathrm{mg}$ of HMX, $100 \mathrm{mg}$ of CP, or $200 \mathrm{mg}$ of a 50/50 mixture for one week and one month at temperatures of 100 and $120{ }^{\circ} \mathrm{C}$. Tubes were backfilled with $1 \%$ Ar in He at a pressure of $\sim 1$ atm. 
The evolved gases were analyzed by gas chromatography. In order to resolve water and ammonia in addition to other gases, a Haysep $\mathrm{C}$ column was used. The packing material is divinylbenzene crosslinked with acrylonitrile. The punching device used to obtain the gas sample from the sealed tubes is shown in Figure 1, and a sample gas chromatogram is shown in Figure 2.

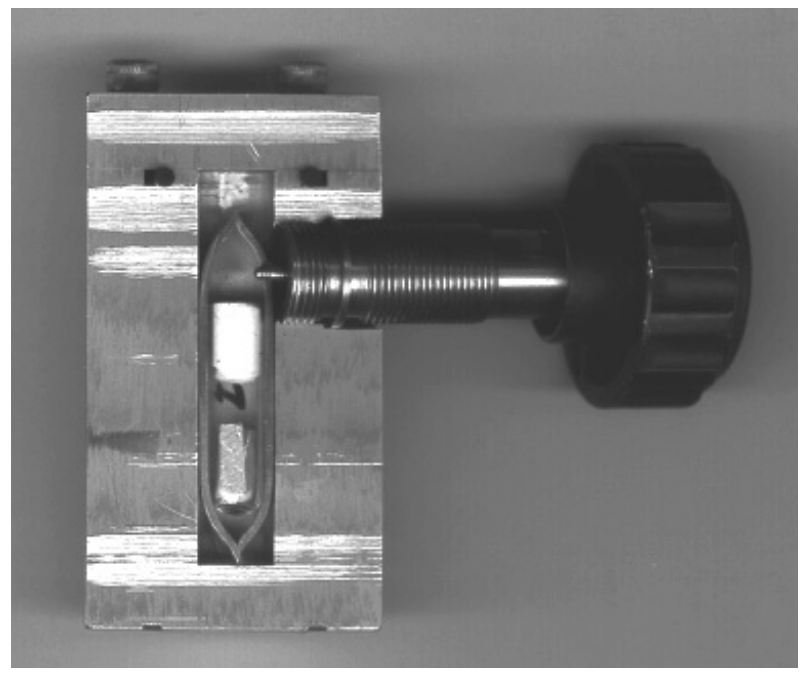

Figure 1. Punching device used to sample the gas from the sealed tubes. The tube has been sawn lengthwise in this photo to show the loading of the sample.

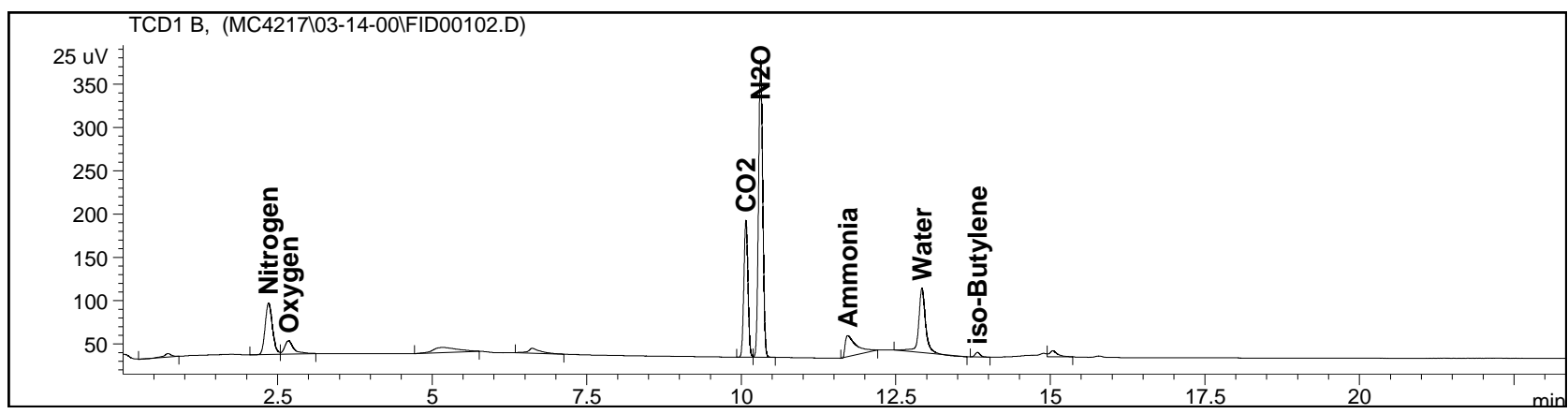

Figure 2. Typical gas chromatogram obtained from an HMX-CP mixture aged for 50 months at $100^{\circ} \mathrm{C}$.

\section{Kinetic Analysis Methods}

Chemical reactions are often treated mathematically as first-order reactions with their temperature dependence described by the Arrhenius rate law: $k=A \exp (-E / R T)$, where $\mathrm{E}$ is the activation energy. At constant temperature, a first-order reaction undergoes an exponential decay with time constant 1/k. As temperature changes, the time constant changes exponentially with a coefficient of E/RT. Even when the reaction is not first-order, it is generally possible to describe the temperature dependence at any specific extent of reaction as an exponential function of temperature. In the simplest form, plotting the inverse of the time for a given reaction extent versus reciprocal 
temperature will be a straight line with slope $-\mathrm{E} / \mathrm{RT}$. More generally, this method is called isoconversional kinetic analysis when $\mathrm{E}$ is determined as a function of reaction extent.

A reaction model we have found to be particularly adaptable to a wide range of materials is the extended Prout-Tompkins model ${ }^{1,2}$

$$
\mathrm{d} \alpha / \mathrm{dt}=k(1-q(1-\alpha))^{m}(1-\alpha)^{n},
$$

where $\alpha$ is the fraction reacted, $n$ is the reaction order, $m$ is a nucleation-growth parameter, and $q$ is an initiation parameter. It has limits of the original Prout-Tompkins model ( $m=n=1$ ), a first-order reaction, and an nth-order reaction, which is equivalent to a gamma distribution of frequency factors. ${ }^{1}$ This reaction model was fitted to some data sets using the LLNL kinetic analysis program Kinetics05. ${ }^{1}$

\section{RESULTS AND DISCUSSION}

\section{A. Long-term Aging Studies of HMX-CP Mixtures in Detonators}

Amounts of $\mathrm{N}_{2} \mathrm{O}, \mathrm{N}_{2}$, and $\mathrm{CO}_{2}$ generated from the HMX-CP mixtures in detonators are shown in Table 1. The fraction of HMX decomposed in each experiment was calculated by summing the mass of $\mathrm{N}_{2} \mathrm{O}, \mathrm{N}_{2}$ (excess from baseline), and $\mathrm{CO}_{2}$ generated and dividing by the mass of HMX (9.2 mg). These results are also shown in Table 1 and compared in Figure 3 to measured weight loss where available. The good agreement between measured and calculated mass loss supports the validity of the method.

The fractions decomposed in these experiments can be used to calibrate a kinetic model for extrapolation to other times and temperatures. An extended Prout-Tompkins model, Equation 1 with reaction order (n) constrained to unity, was calibrated using Kinetics05. The results are shown in Figure 4. The reaction is strongly acceleratory, or autocatalytic, as indicated by the $\mathrm{m}$ value of 1.83 . This means that the reaction quickly takes off after a long period of latency (induction period).

Table 1. Gas-yield data from Sandia long-term aging of HMX-CP mixtures in detonators. Dissappearance of ambient oxygen indicates some early oxidation reactions, and lack of oxygen in the heated tubes indicates no contamination by air during sampling.

\begin{tabular}{|c|c|c|c|c|c|c|c|}
\hline $\begin{array}{l}\text { Aging } \\
\text { time (mo) }\end{array}$ & $\begin{array}{l}\text { Aging } \\
\text { temp, }{ }^{\circ} \mathrm{C}\end{array}$ & $\mathrm{N}_{2}(\mu \mathrm{L})$ & $\mathrm{O}_{2}(\mu \mathrm{L})$ & $\mathrm{CO}_{2}(\mu \mathrm{L})$ & $\mathrm{N}_{2} \mathrm{O}(\mu \mathrm{L})$ & $\begin{array}{l}\mathrm{mg} \mathrm{N}_{2} \mathrm{O}+ \\
\Delta \mathrm{N}_{2}+\mathrm{CO}_{2} \\
\end{array}$ & $\begin{array}{l}\text { \% HMX } \\
\text { decomp. }\end{array}$ \\
\hline 0.0 & baseline & 5.8 & 0.9 & 0.0 & 0.0 & $5.00 \mathrm{E}-07$ & 0.005 \\
\hline 50.3 & ambient & 5.3 & 0.8 & 0.0 & 0.0 & $-7.50 \mathrm{E}-08$ & -0.001 \\
\hline 24.5 & 50 & 5.2 & 0.4 & 0.0 & 0.5 & 7.08E-07 & 0.008 \\
\hline 50.0 & 50 & 4.8 & 0.1 & 0.1 & 0.5 & 5.32E-07 & 0.006 \\
\hline 24.0 & 70 & 6.6 & -0.1 & 0.6 & 2.1 & 6.63E-06 & 0.072 \\
\hline 50.2 & 70 & 6.3 & -0.3 & 0.8 & 2.4 & 7.42E-06 & 0.081 \\
\hline 24.0 & 100 & 13.1 & -0.1 & 8.7 & 34.2 & 9.39E-05 & 1.021 \\
\hline 50.2 & 100 & 122.7 & 0.1 & 105.8 & 405.8 & 1.15E-03 & 12.52 \\
\hline
\end{tabular}




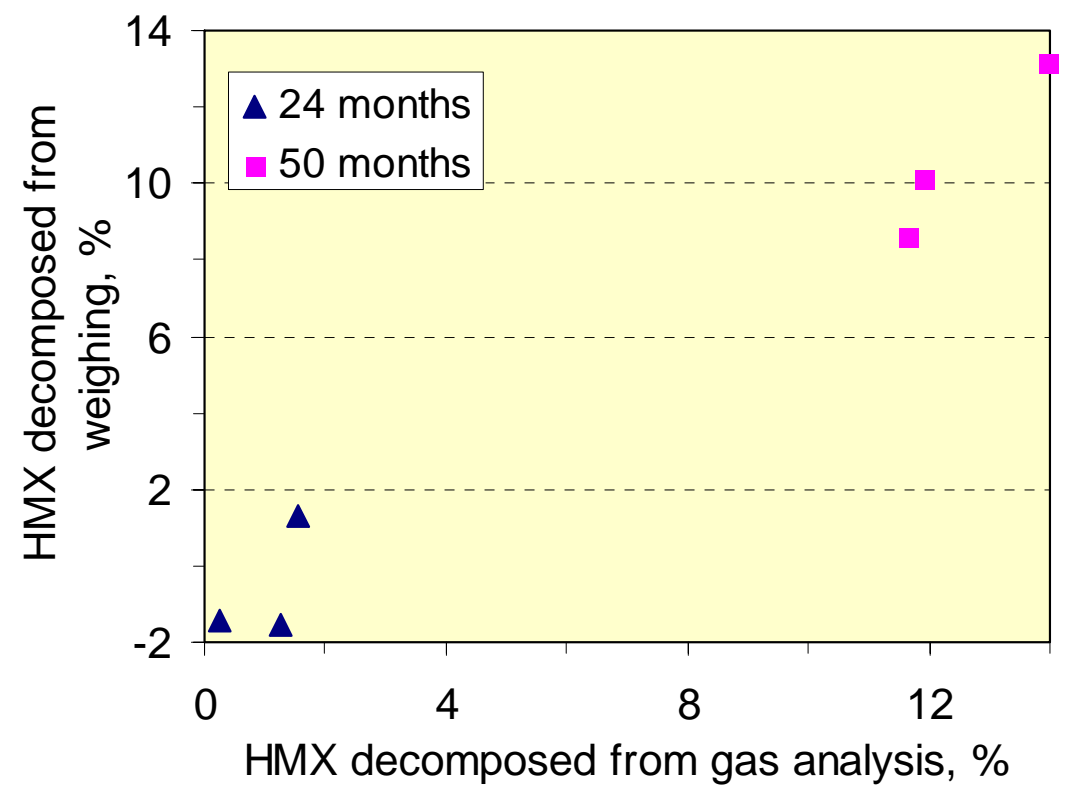

Figure 3. Correlation of percent of HMX decomposed as calculated from gas analysis $\left(\mathrm{N}_{2} \mathrm{O}+\right.$ excess $\mathrm{N}_{2}+\mathrm{CO}_{2}$ ) in Table 1 and as measured directly by weight change in the Sandia detonator aging studies. The two methods agree reasonably well.
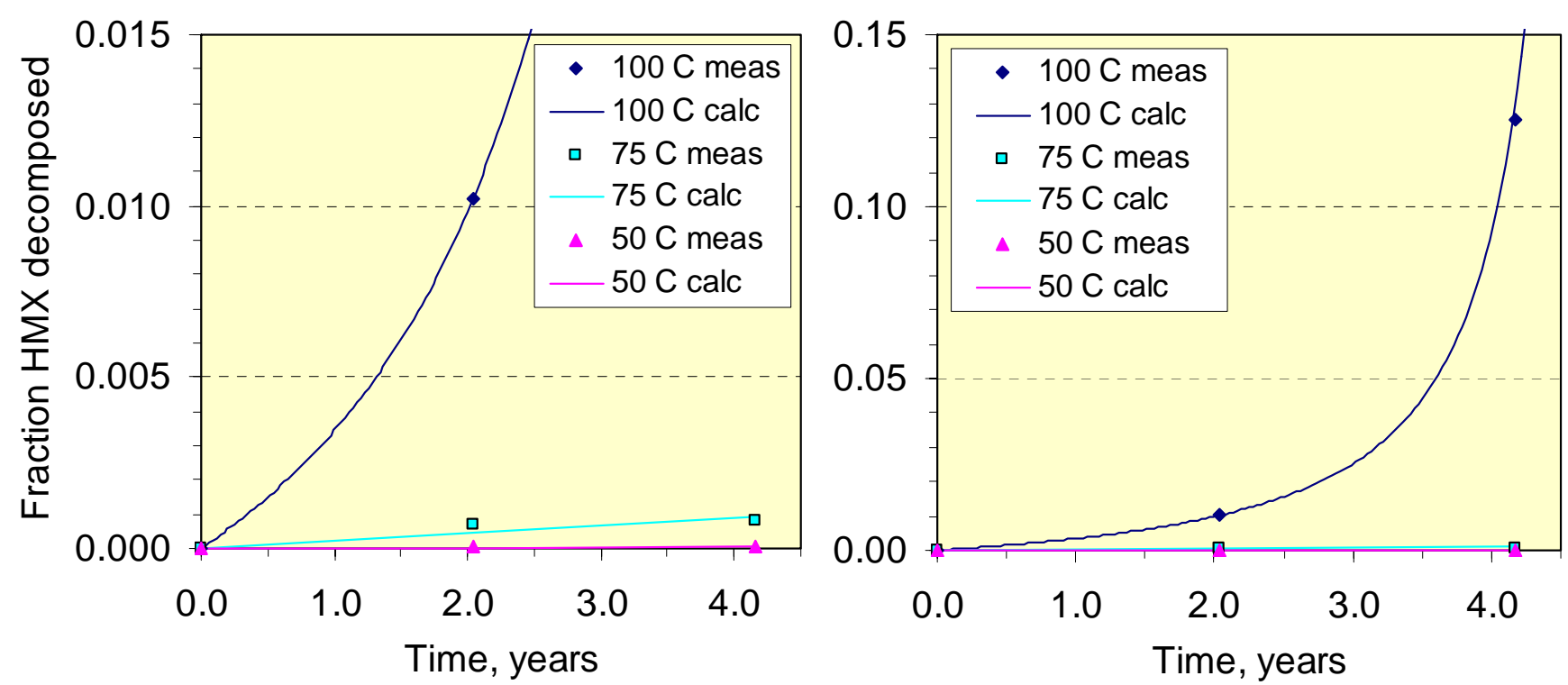

Figure 4. Observed and calculated fractions of HMX decomposed for a fit of an extended ProutTompkins nucleation-growth model to the Sandia detonator aging studies. The kinetic parameters are $A=8.95 \times 10^{8} \mathrm{~s}^{-1}, \mathrm{E}=109.7 \mathrm{~kJ} / \mathrm{mol}, \mathrm{m}=1.83$, and $\mathrm{n}=1.00$. Two scales are shown for a better view of the comparison between experiment and calculation. The acceleratory nature of reaction causes it to be nearly complete by 5 years at $100{ }^{\circ} \mathrm{C}$. 


\section{B. HMX decomposition kinetics}

To assess whether the amount of gas generation from the detonator experiments is greater than expected for HMX alone, results from a variety of HMX experiments are compiled and analyzed. These results were obtained from open-pan TGA, sealed-pan DSC, and gas-generation measurements at high and low temperatures. Data was taken from the literature ${ }^{3,4}$ and from experiments conducted specifically for this work. The objectives are to determine whether the reaction follows a single activation energy over a wide temperature range and to estimate rates of gas generation rates at the detonator aging temperatures $\left(50-100{ }^{\circ} \mathrm{C}\right)$.

Kinetic analysis of isothermal TGA data from 190 to $250{ }^{\circ} \mathrm{C}$ and nonisothermal TGA and DSC data for heating rates from 0.1 to 1.0 are summarized in Table 2 and Figures 5-7. The main stage of the reaction (ignoring minor mass losses due to moisture and sources near the $\beta \rightarrow \delta$ phase transition) is well characterized by a single autocatalytic reaction, even though deviation from the model indicates the presence of multiple rate processes. The deviation from a single peak is most noticeable at the slowest DSC heating rate in Figure 7.

For the open-pan isothermal TGA experiments, a 2\% weight loss occurred essentially during sample heatup, likely occurring due to loss of residual moisture. Kinetic parameters are reported for only the main stage of HMX decomposition in the ramped TGA and DSC experiments. In the TGA-DTA experiments, a weight loss process occurred just above the solid-solid phase transition, but the amount of weight loss was inversely proportional to heating rate. At high heating rates, the weight loss spikes might be associated with either a small exotherm or endotherm in the DTA and may be due to impurities. At low heating rates where the mass loss was larger, there was a larger exotherm, which may result from interaction with the purge gas (residual moisture or oxygen) during the extended heatup. It is not obvious that any of these early signals are related to HMX decomposition itself. In the DSC experiments, no early processes could be distinguished from the phase transition endotherms. Consequently, we do not have any convincing evidence in any of the three data sets that there is a HMX decomposition process other than the main reaction, i.e., the continuous and obvious process occurring, for example, between 200 and $270{ }^{\circ} \mathrm{C}$ in Figure 6.

Even though a good fit to the main reaction can be obtained with a single nucleation-growth reaction model, it must be emphasized that it is not a single homogeneous process. Inflections in reaction rate plots show clear evidence for multiple overlapping processes. Empirical models having three parallel reactions have been developed to attain a marginally better fit, ${ }^{3}$ but they have not been used in this study.

Behrens and Bulusu ${ }^{4}$ studied the decomposition of HMX using evolved gases as a measure of the reaction. This particular paper added data in the $175-200{ }^{\circ} \mathrm{C}$ range to earlier work from 210 to $235^{\circ} \mathrm{C}$. The reaction showed clear evidence of induction and acceleratory phases, and HMX sublimation contributed significantly to the gas formation rate in the early stages of the reaction. Individual gas species had different release kinetics, e.g., evolution of $\mathrm{CH}_{2} \mathrm{O}$ lags that of $\mathrm{N}_{2} \mathrm{O}$.

Behrens and Bulusu ${ }^{4}$ describe their kinetics in terms of three sequential processes, which over the small reaction interval studied, are essentially straight lines. The first process is an induction period, in which gas generation occurs, and the induction time is 
described by an Arrhenius-like relationship. The acceleratory phase is described by two sequential first-order reactions operating over time intervals that are calculated to achieve prescribed fractions reacted.

Equation (1) automatically achieves these characteristics with a continuous function. Consequently, we reanalyzed the results of Behrens and Bulusu using our approach. The results are shown in Figure 8. The model fits the data well. The resulting A and E parameters are intermediate between Behrens' first and second acceleratory phase Arrhenius parameters. Figure 9 shows a similar comparison to the fractions reacted calculated from the main reaction of our kinetic expression calibrated on openpan TGA data (Table 2). The agreement is very good at $200{ }^{\circ} \mathrm{C}$ and within a factor of two at $175^{\circ} \mathrm{C}$. The gas evolution data is more strongly autocatalytic, and there may be a contribution from sublimation to the TGA model.

Table 2. Summary of kinetic parameters from thermal analysis of HMX sample B-844.

\begin{tabular}{|c|c|c|c|c|c|}
\hline & fraction & $\mathbf{A}, \mathbf{s}^{-\mathbf{1}}$ & $\mathbf{E , ~} \mathbf{~ k J} / \mathbf{m o l}$ & $\mathbf{~ m}$ & $\mathbf{n}$ \\
\hline Isothermal TGA & 0.02 & $7.04 \times 10^{7}$ & 101.1 & 0.00 & 1.00 \\
\hline (open pan, $190-250^{\circ} \mathrm{C}$ ) & 0.98 & $5.84 \times 10^{13}$ & 167.2 & 0.691 & 0.823 \\
\hline Ramped TGA & 1.00 & $1.087 \times 10^{11}$ & 141.4 & 0.539 & 0.483 \\
\hline (open pan, $0.1-1.0^{\circ} \mathrm{C} / \mathrm{min}$ ) & see text & & & & \\
\hline Ramped DSC & 1.00 & $3.81 \times 10^{13}$ & 164.4 & 0.635 & 0.320 \\
\hline (hermetically sealed pan) & see text & & & & \\
\hline
\end{tabular}

Another source of HMX decomposition data comes from multi-year, lowtemperature, sealed-tube experiments at Sandia-NM. $\mathrm{N}_{2} \mathrm{O}$ generation over 5 years for temperatures ranging from 60 to $120^{\circ} \mathrm{C}$ are shown in Figure 10. For example, these experiments achieved $5 \% \mathrm{HMX}$ decomposition in 2.7 years at $120^{\circ} \mathrm{C}$, based on the conversion of HMX nitrogen to $\mathrm{N}_{2} \mathrm{O}$, which is the only gas reported. By analogy to the aging experiments summarized in Table 1, we estimate that the fraction reacted as measured by mass loss of HMX would be only half a great as that estimated from nitrogen conversion. Similarly, the maximum yield at $100{ }^{\circ} \mathrm{C}$ (as measured by $\mathrm{N}_{2} \mathrm{O}$ generation) was $1 \%$ from 1.5 to 3.5 years. These and additional $80{ }^{\circ} \mathrm{C}$ experiments result in a low apparent activation energy of $96 \mathrm{~kJ} / \mathrm{mol}$. However, the flatness in $100{ }^{\circ} \mathrm{C}$ gas yield from 1.5 to 3.5 years is reminiscent of a faster process for the first percent or so of decomposition in thermal analysis experiments and may not be representative of the bulk reaction.

A fundamental requirement for kinetic analysis is that unless the reaction is demonstrated to follow an assumed model exactly, one must use comparable extents of reactions at all measurement temperatures for the $\mathrm{A}$ and $\mathrm{E}$ determination or they can be distorted by the characteristics of the model assumed — either higher or lower than the true values. Consequently, kinetics parameters calibrated on this low conversion data are not particularly reliable. Instead, we view this data, particularly the rate at $120^{\circ} \mathrm{C}$, as an excellent way to test the extrapolation of the more extensive work at higher temperatures to the conditions of interest for the accelerated aging tests. 

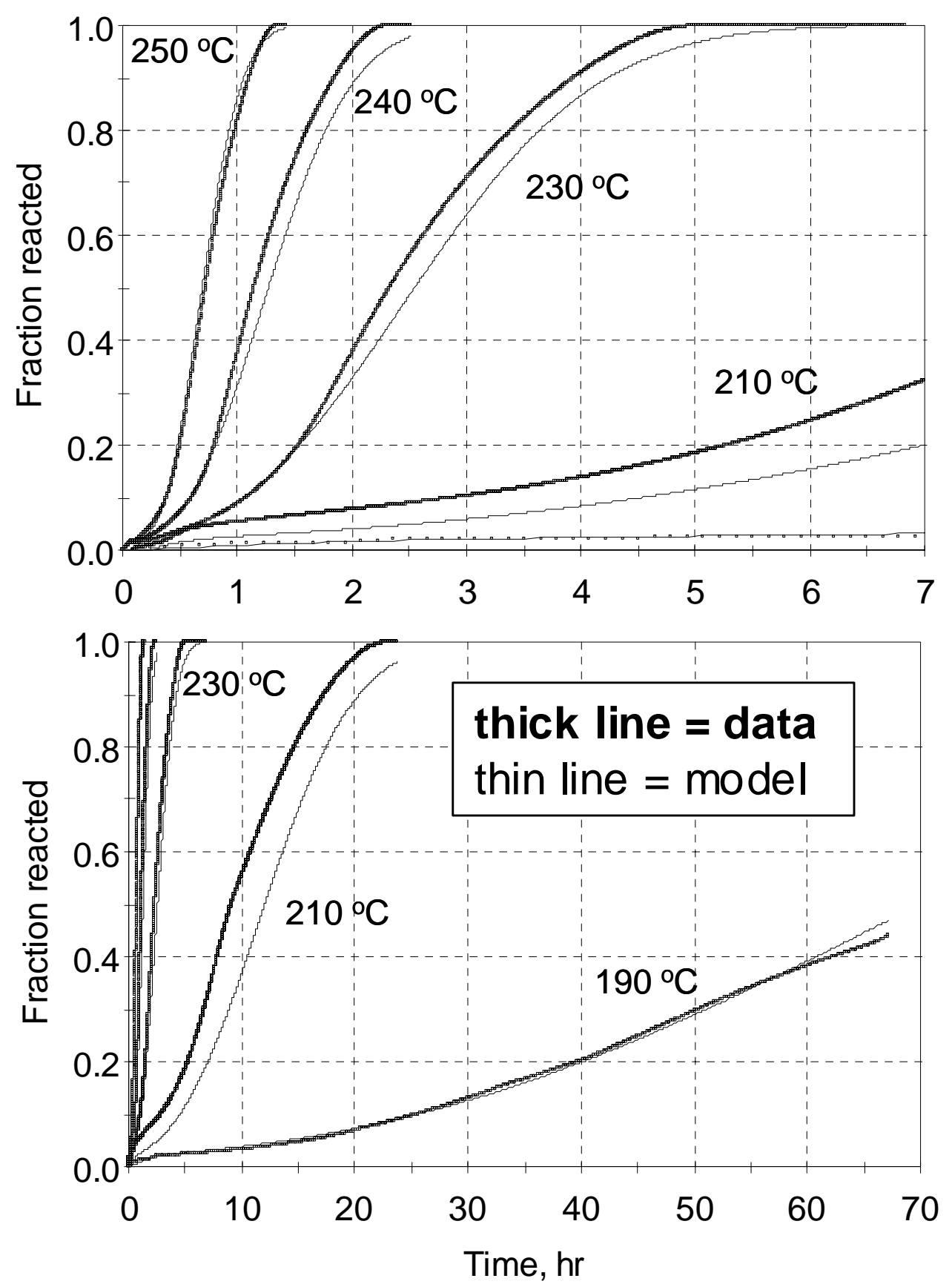

Figure 5. Comparison of model parameters in Table 2 for isothermal weight loss from HMX (open-pan TGA). Two time scales are shown enable a comparison over the entire temperature range. Only partial reaction was achieved at $190{ }^{\circ} \mathrm{C}$ due to the slowness of the reaction. The autocatalytic character $(\mathrm{m}>0)$ is particularly evident at the lower temperatures where it is clearly separated from thermal heatup. 


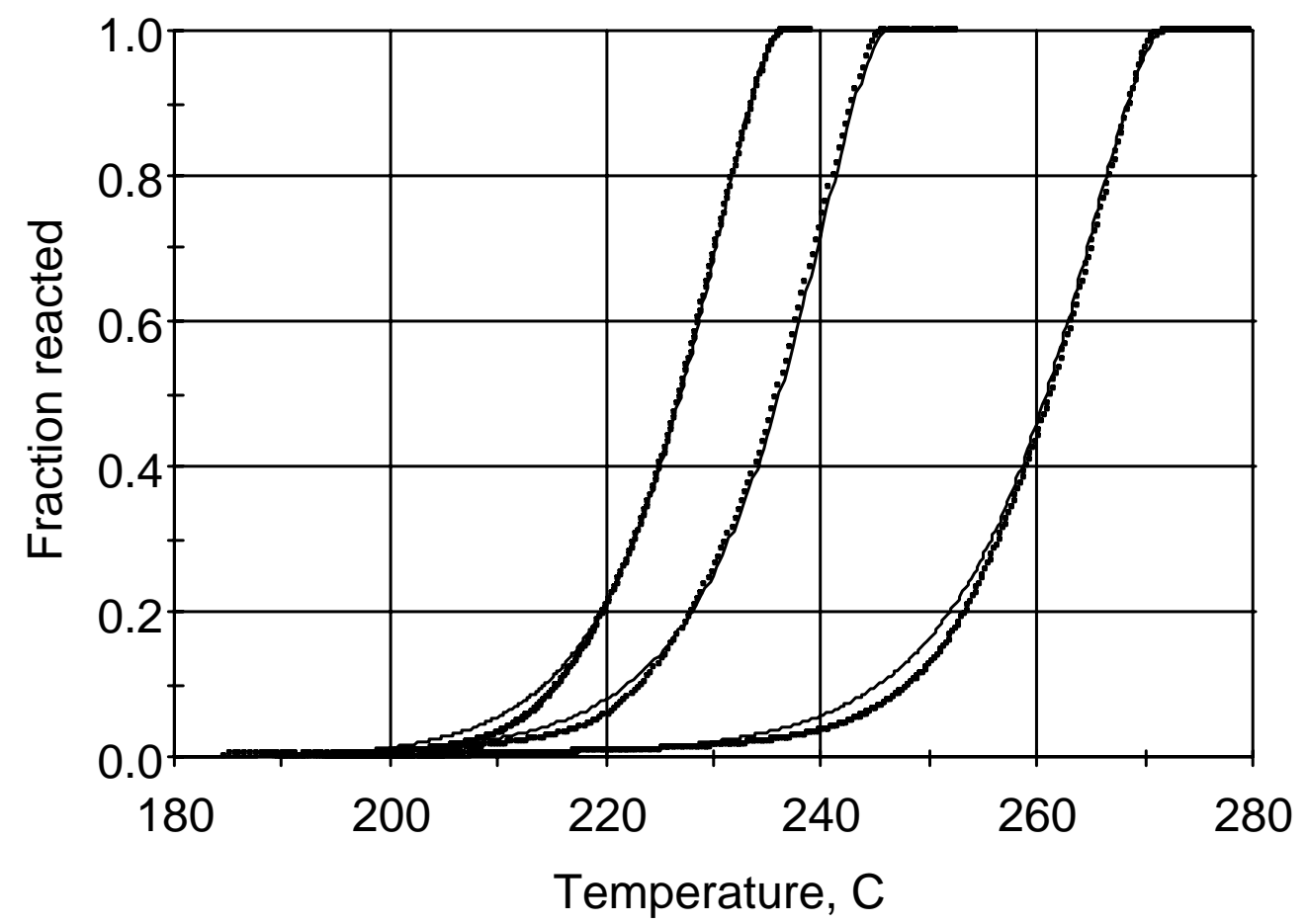

Figure 6. Comparison of model and experiment for weight loss (open-pan TGA) at heating rates of $0.1,0.2$, and $1.0{ }^{\circ} \mathrm{C} / \mathrm{min}$, from left to right, respectively. The thin line is the model.

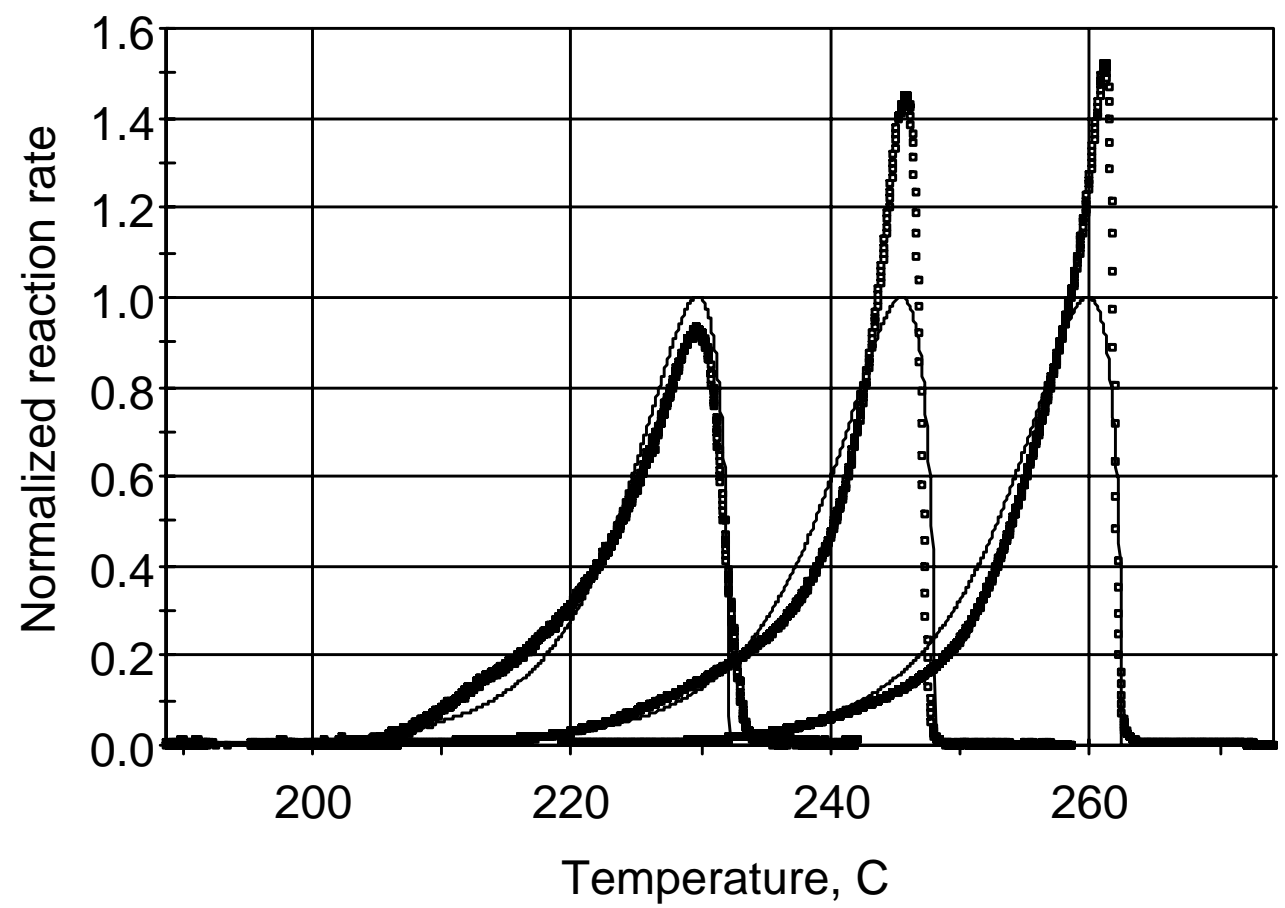

Figure 7. Comparison of model (lines) and experiment (points) for DSC heat release in a hermetically sealed pan at heating rates of $0.1,0.35$, and $1.0^{\circ} \mathrm{C} / \mathrm{min}$, from left to right, respectively. The integrals under the measured and calculated curves are equal. 


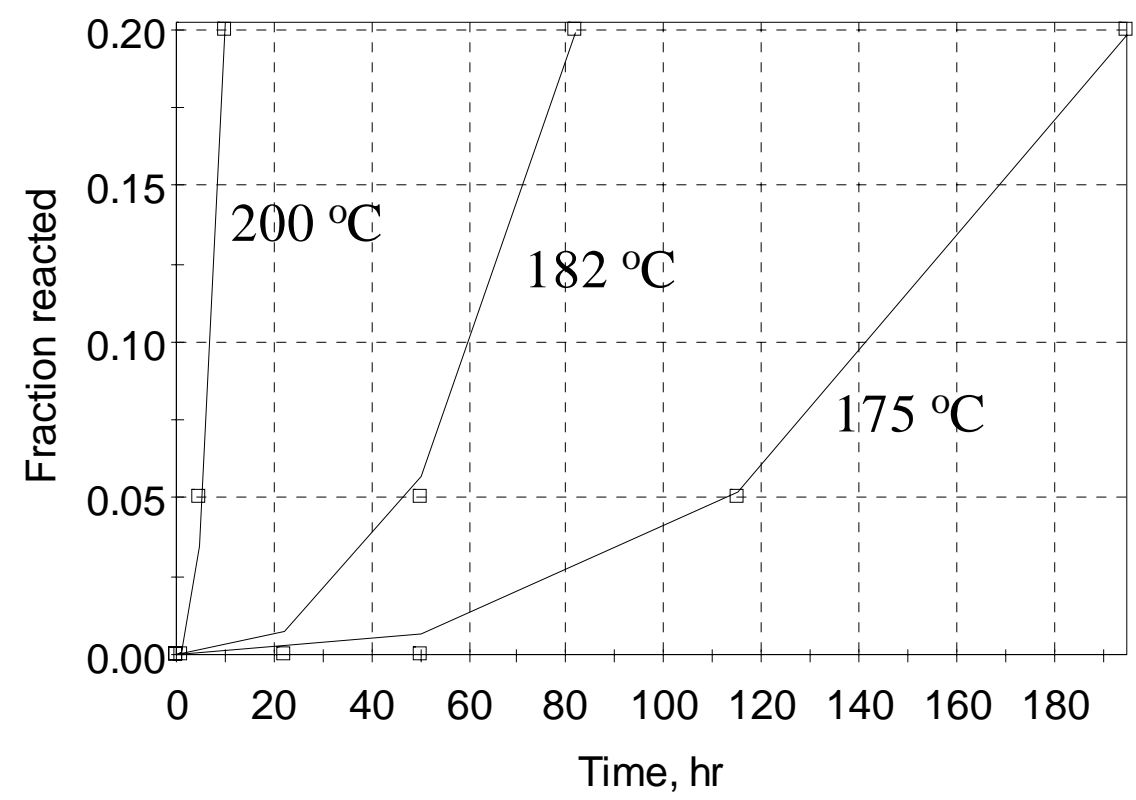

Figure 8. Fit of the extended Prout-Tompkins autocatalytic model to the low temperature HMX decomposition data of Behrens and Bulusu. ${ }^{4}$ Equation (1) ordinarily uses q=0.99, but in this case, improved fits were obtained using $\mathrm{q}=0.9999$ due to the substantial induction period. The resulting kinetic parameters were $A=7.71 \times 10^{18} \mathrm{~s}^{-1}, \mathrm{E}=210.1 \mathrm{~kJ} / \mathrm{mol}$, and $\mathrm{m}=0.676$. A full model calculation is curved as in Figure 4, but in this case, a straight line connects the calculated points at the experimental times.

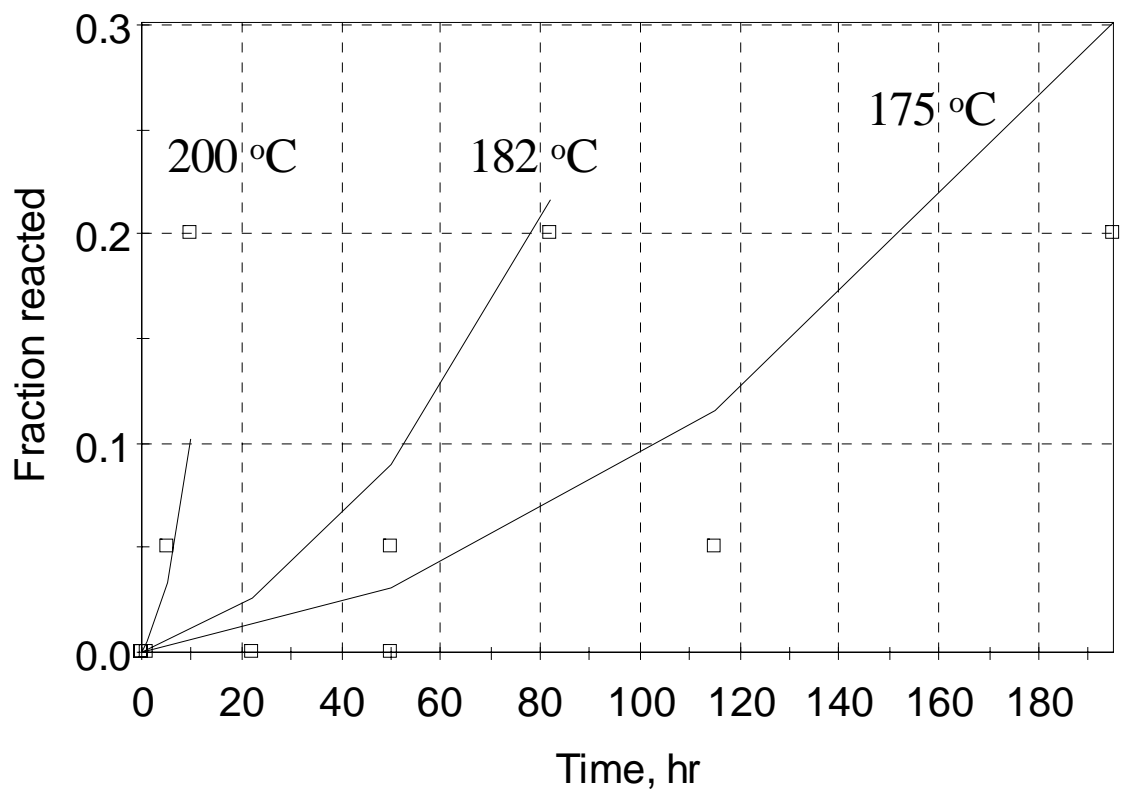

Figure 9. Comparison of HMX fractions reacted estimated by Behrens and Bulusu (SNL) from gas evolution data $^{4}$ with those calculated from kinetics derived at LLNL from isothermal TGA kinetics (Table 2). 


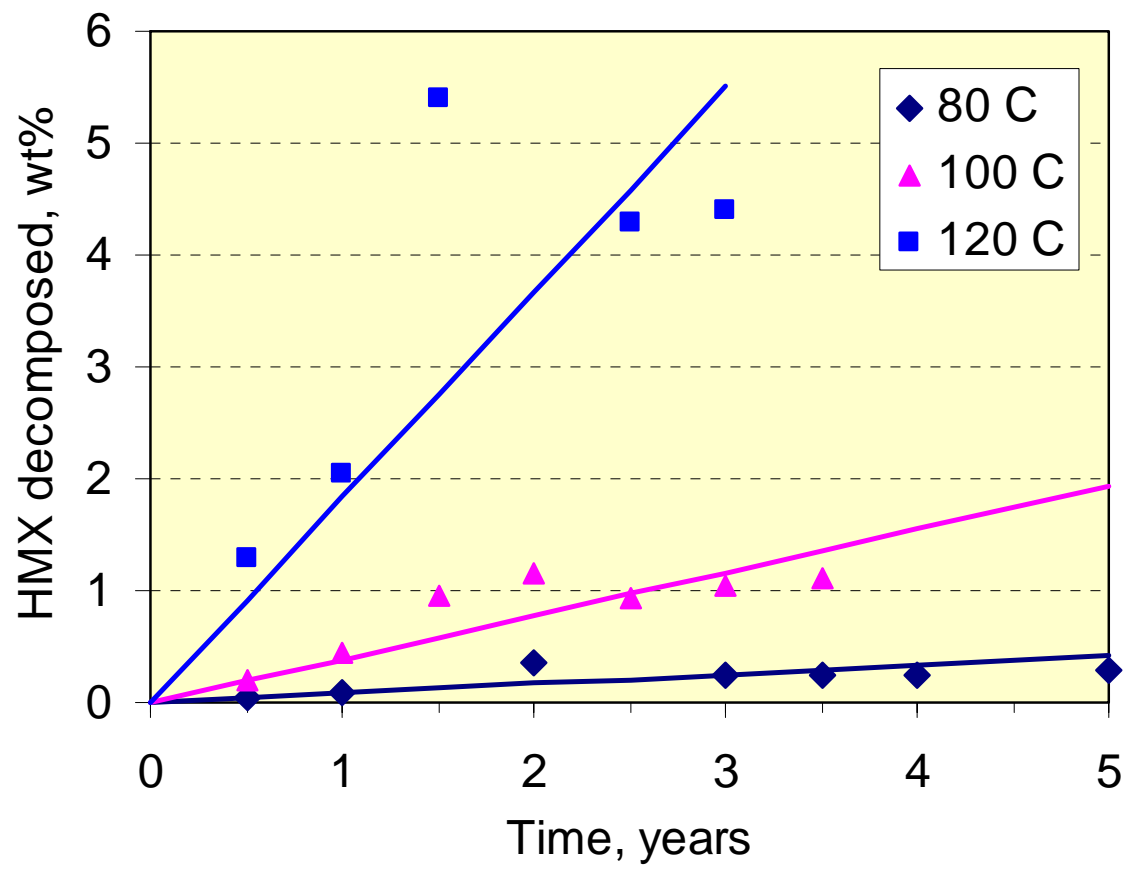

Figure 10. $\mathrm{N}_{2} \mathrm{O}$ gas yields as a function of time from long-term HMX decomposition experiments. Based on an analogy to the more complete product analysis in Table 1, the amount of mass loss from HMX would be only half as great.

The ultimate question at hand is whether these various kinetic expressions are consistent with the accelerated aging test data and therefore are a reliable estimator of storage lifetime of components containing HMX. The results of these various kinetic experiments and models are summarized in Figure 11. Here we have chosen to compare the time to achieve 10\% HMX decomposition, which would certainly raise concern about HMX performance in a component. The various experiments actually agree very well and imply an overall activation energy of about $165 \mathrm{~kJ} / \mathrm{mol}$ for the first $10 \%$ of the reaction from 120 to $270{ }^{\circ} \mathrm{C}$. The reaction time at the lower temperature $\left(100{ }^{\circ} \mathrm{C}\right)$ time of the sealed-tube experiments falls above the trend line from the other experiments, but it is not as reliable due to the extremely low extent of reaction, as discussed in the preceding paragraph. The $80{ }^{\circ} \mathrm{C}$ result from Figure 10 would continue that trend line, but it is an even less reliable basis to estimate a time for $10 \%$ conversion due to the very low extent of reaction.

The gas yields from the detonator aging tests are clearly greater than for HMX decomposition alone by a factor of about 30, since all the results from disparate experiments follow the same basic trend line from $270{ }^{\circ} \mathrm{C}$ down to at least $120{ }^{\circ} \mathrm{C}$. Even though the $100{ }^{\circ} \mathrm{C}$ data point for HMX alone indicates nearly a tenfold enhancement in HMX decomposition in the CP-HMX detonator. Additional information supporting an enhanced HMX decomposition in the detonator aging tests is given in the following section, which explores the decomposition of HMX-CP mixtures. 


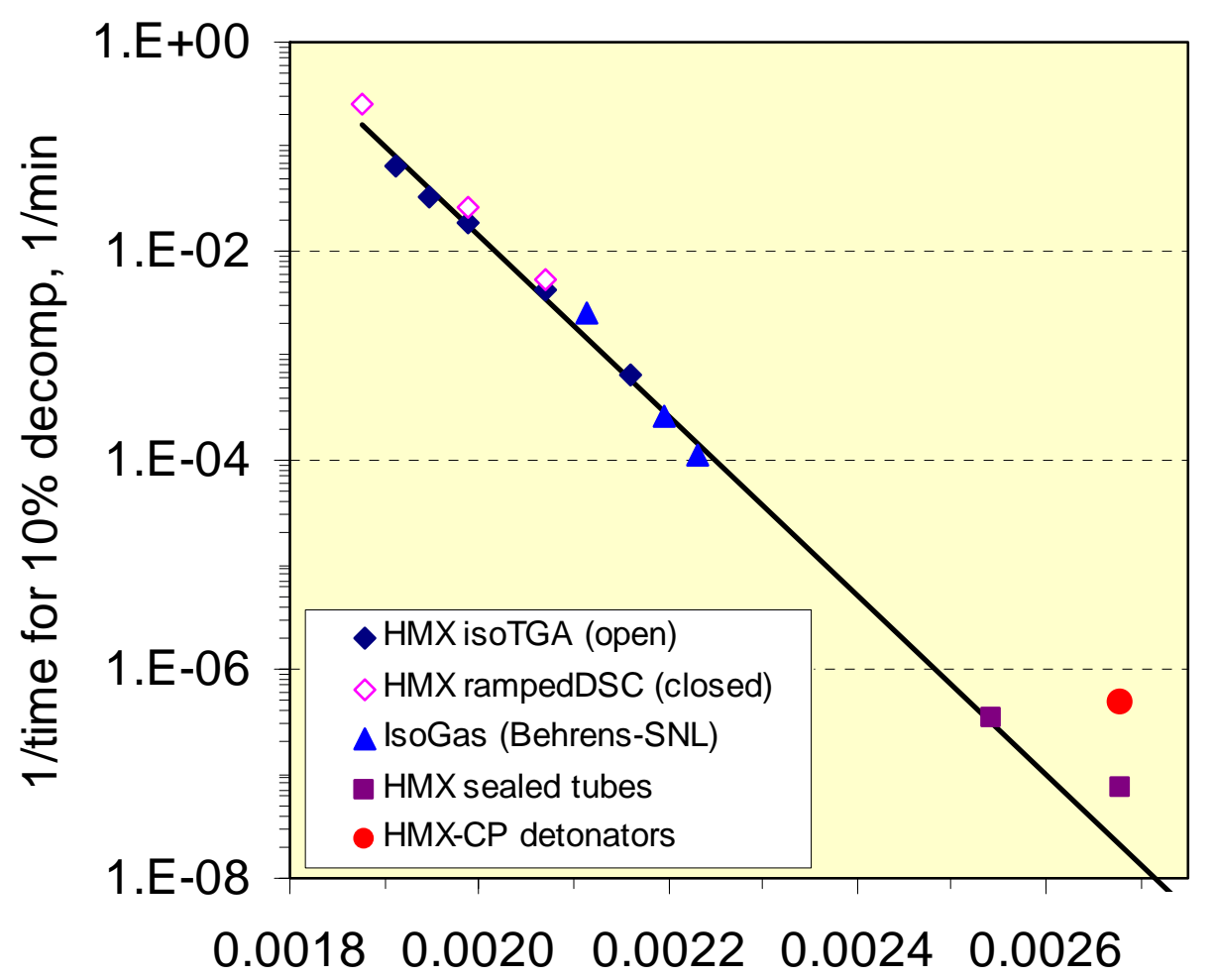

$1 /$ Temperature, $1 / \mathrm{K}$

Figure 11. Compilation of rate constants for HMX decomposition from a variety of experiments. Rate constants are expressed in terms of the reciprocal time needed for $10 \%$ decomposition. The filled squares for the sealed-tube experiments represent a most likely value based on estimated mass loss.

That HMX decomposition follows an Arrhenius extrapolation over such a wide range of times and temperatures may be surprising to some, but it is by no means unique. Figure 12 reproduces four such figures from the literature involving hydrocarbon generation. The objective of this work was to derive Arrhenius parameters for extrapolation to tens of millions of years. While some controversy remains, the ability to make such an extrapolation is generally accepted by geochemists. The fourth figure is actually a detailed free-radical calculation that helps explain the results. The reaction is a complex mix of initiation, propagation, and termination reactions, and the apparent activation energy is a complicated average of those reactions. Even though the mix changes as a function of temperature, it changes in a continuous manner, so the overall reaction still follows an Arrhenius law. The difference in apparent activation energy at low and high pressure is due to a different weighting of initiation, propagation, and termination reactions - the propagation chain length is shorter, so the higher energy initiation reactions figure more prominently. 

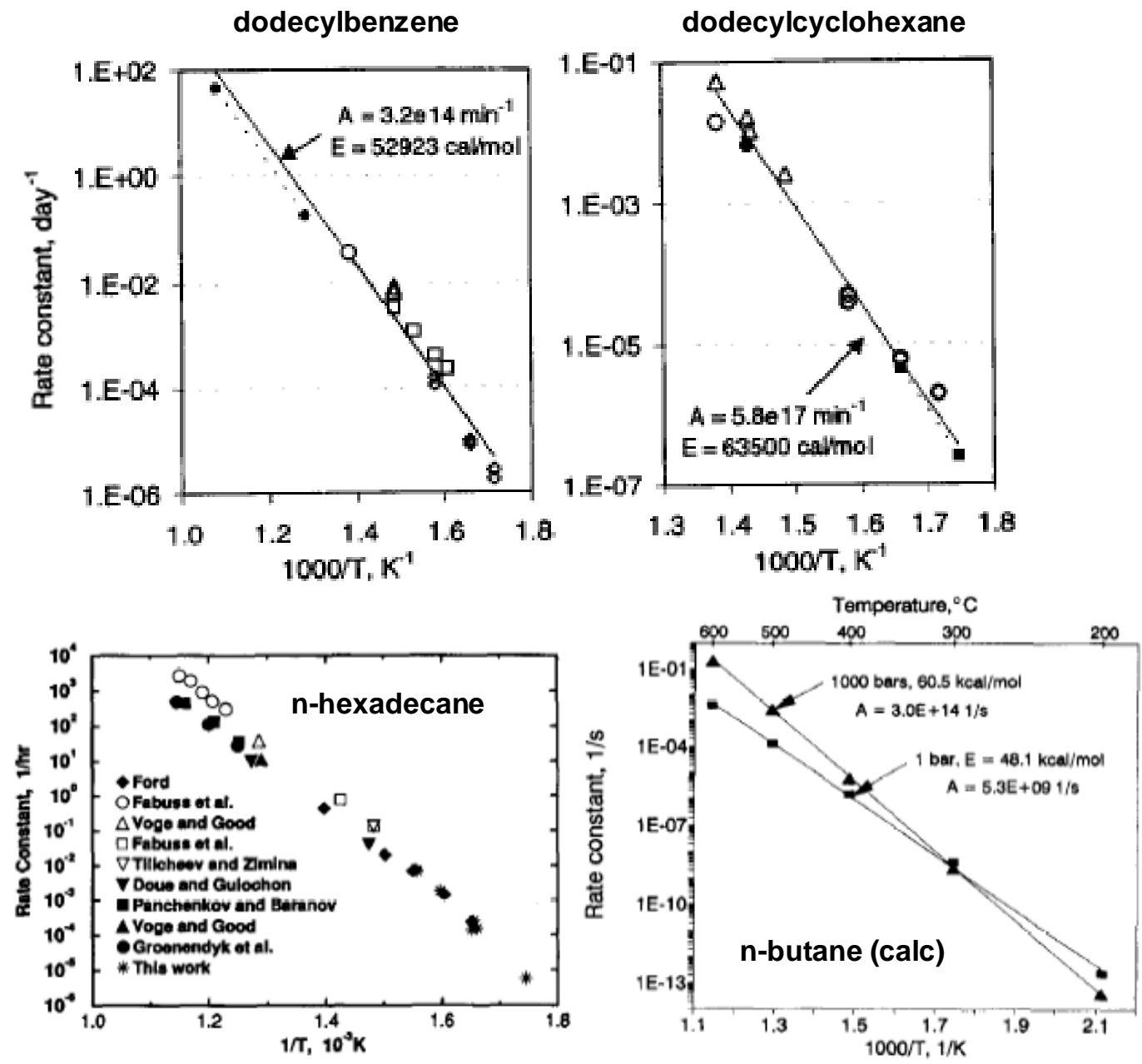

Figure 12. Compilation of hydrocarbon cracking rate constants showing linearity over seven to nine orders of magnitude change in rate constant for dodecylbenzene, ${ }^{5}$ dodecylcyclohexane, ${ }^{5}$ and n-hexadecane; ${ }^{6}$ and a detailed free-radical calculation for butane showing similar linearity. ${ }^{6}$

\section{High-Temperature Decomposition of CP and CP-HMX mixtures}

The enhanced decomposition of HMX in the detonator accelerated aging experiments over that expected for HMX alone suggests that $\mathrm{CP}$ and HMX are interacting with each other. Consequently, a series of DSC experiments were performed with CP by itself and CP mixed with HMX. The experiments used hermetically sealed pans, and the reaction rate was monitored by heat flow. The working hypothesis was that trace gases evolved from the early stages of CP decomposition accelerate the decomposition of HMX. There was some variability in the measured reaction rates, so the most representative runs from at least three replicates was used in this analysis.

Examples of the heat release for CP by itself at three different heating rates is shown in Figure 13. These reaction profiles are similar to those reported by Massis et al. for a sealed pan. ${ }^{7}$ Due to variability of the reaction profiles, no detailed kinetic analysis was attempted. However, analysis of the shift in $\mathrm{T}_{\max }$ of the sharp exotherm, using Kissinger's method, ${ }^{8}$ yielded an activation energy of $196.9 \mathrm{~kJ} / \mathrm{mol}$. Searcy and Shanahan $^{9}$ report that the decomposition occurs in three stages. Stage I is an endothermic 


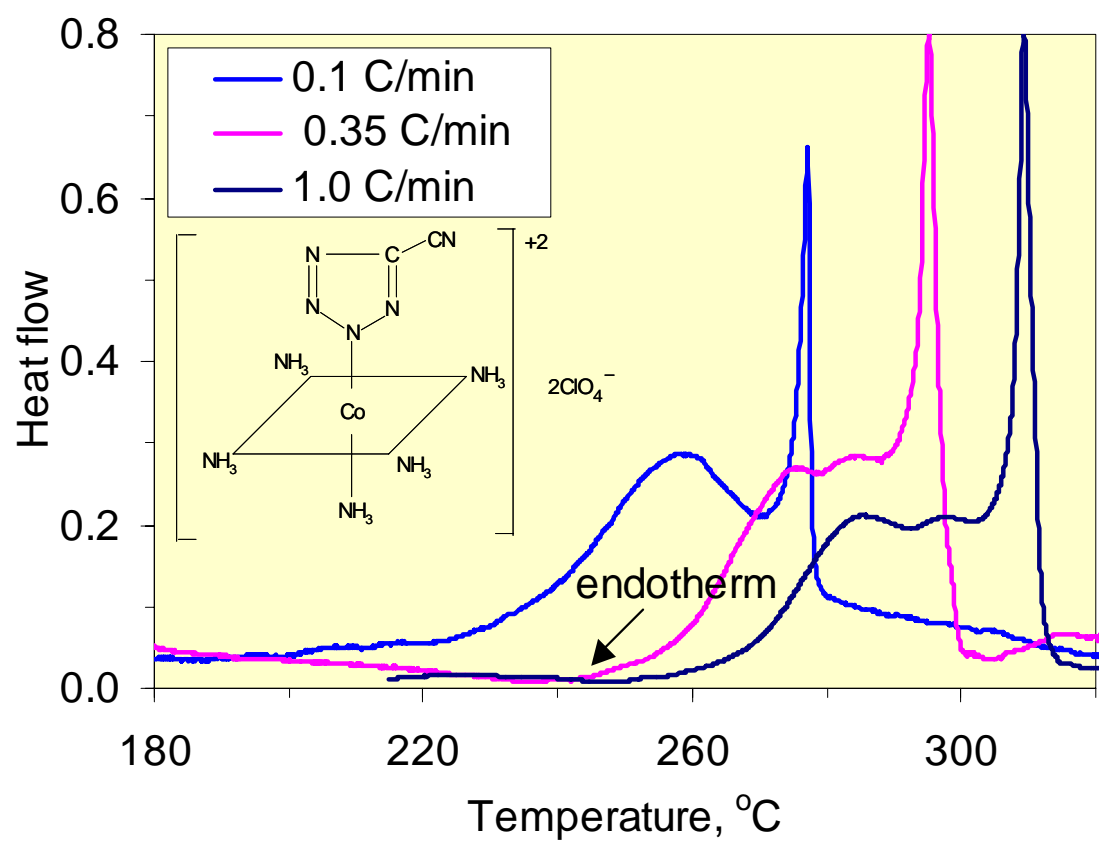

Figure 13. Reaction profiles for decomposition of $\mathrm{CP}$ by itself. The first stage of decomposition gives the endotherm most evident for $0.35{ }^{\circ} \mathrm{C} / \mathrm{min}$ at $240{ }^{\circ} \mathrm{C}$.

process that includes the dissociation of ammonia ligands from the cobalt atom, rearrangement of the 5-cyanotetrazolato ligand, and oxidation of the cobalt to the +2 oxidation state. Stage II is the oxidation of the ligands around the cobalt atom by the perchlorate ion, and Stage III is the oxidation of the residual solid products by the perchorate ion. Because the decomposition in a open system occurs faster, more or less at the temperature of the endotherm in a closed system, it has been postulated that ammonia inhibits the exothermic decomposition. ${ }^{13}$ However, the endotherm itself appears to be accelerated by ammonia. ${ }^{10}$ Regardless of the details of the complete decomposition mechanism, it is possible that the ammonia liberated during the early, endothermic stage of CP might react with HMX to accelerate exothermic decomposition reactions for HMX.

To investigate the possibility of acceleration of HMX decomposition by early CP gaseous products, mixtures of $\mathrm{CP}$ and $\mathrm{HMX}$ were heated at both a constant temperature and a constant heating rate. In both cases, there is clear evidence for acceleration of HMX decomposition by CP.

The results for ramped heating in hermetically sealed DSC pans are shown in Figure 14. The primary exotherm of the mixture is clearly $\sim 20{ }^{\circ} \mathrm{C}$ lower than HMX, whose exotherm precedes that of $\mathrm{CP}$ by a similar amount. The $20{ }^{\circ} \mathrm{C}$ shift in the reaction profile of the mixture compared to neat HMX corresponds to an increase in the reaction rate by a factor of 6 . The very beginning of the endotherm for $\mathrm{CP}$ alone, particularly evident at a heating rate of $0.35^{\circ} \mathrm{C} / \mathrm{min}$, is similar to the beginning of the exotherm of the mixture. The peak of the neat CP endotherm corresponds to the early stages of HMX decomposition by itself. These simple observations provide support for the hypothesis that ammonia released from CP enhances the decomposition of HMX. The higher temperature peaks in the mixture decomposition probably relate to oxidation of remaining material by the perchlorate ion. 

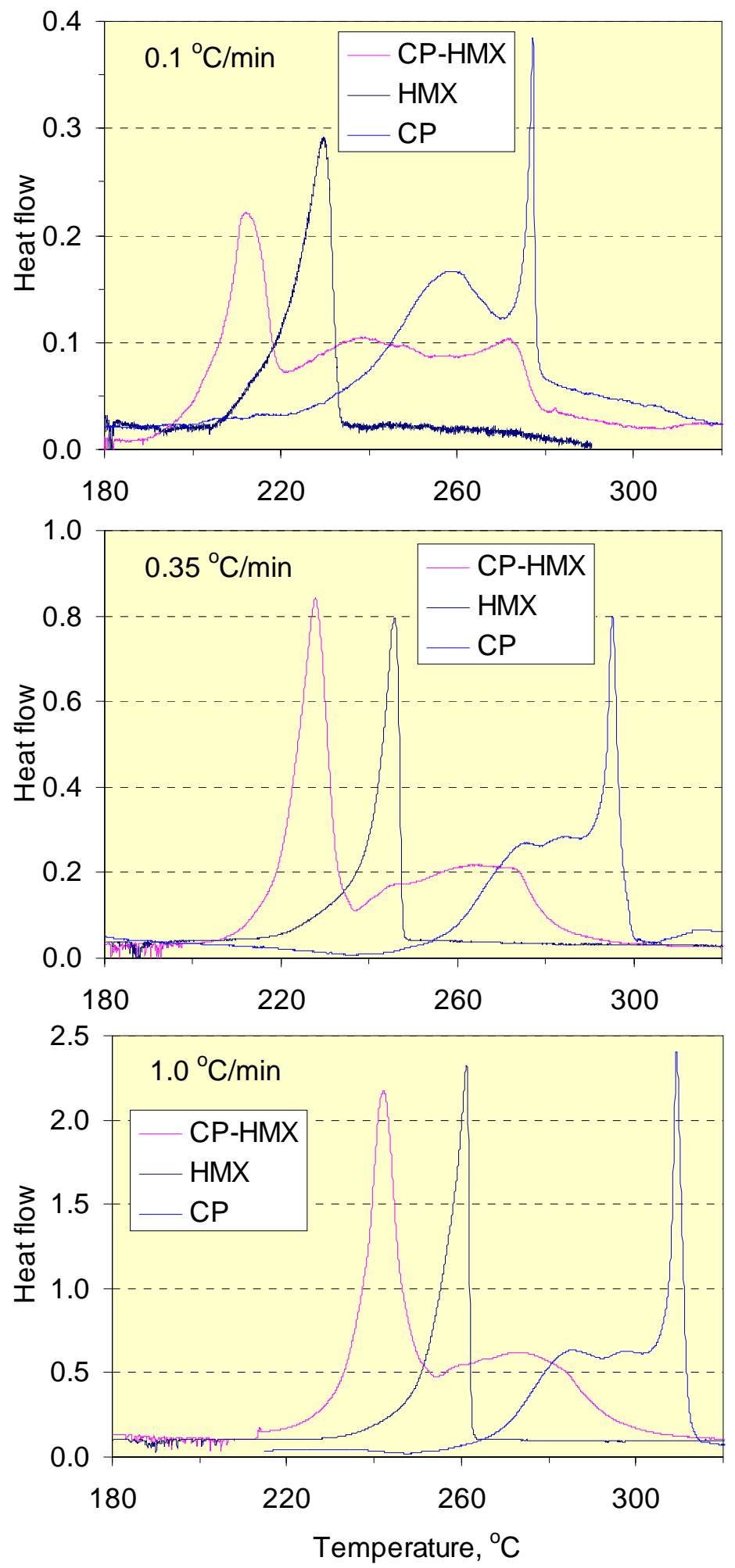

Figure 14. Comparison of DSC reaction profiles of HMX, CP, and CP-HMX mixtures. Note that the endothermic reaction for $\mathrm{CP}$ is coincident with the exothermic decomposition of HMX, and it is particularly evident in the profiles at $0.35^{\circ} \mathrm{C} / \mathrm{min}$. Even though the CP-HMX mixture decomposes faster than either individually, one should compare the mixture $\mathrm{T}_{\max }$ of $240{ }^{\circ} \mathrm{C}$ at 1 ${ }^{\circ} \mathrm{C} / \mathrm{min}$ to the corresponding values of $180{ }^{\circ} \mathrm{C}$ for PETN, $215{ }^{\circ} \mathrm{C}$ for RDX, and $275{ }^{\circ} \mathrm{C}$ for TNT. 
Due to the complexity of the reaction profile of the mixture in Figure 14, no comprehensive kinetic analysis was attempted. However, the first exothermic peak in the HMX-CP mixture is described fairly well by a nucleation-growth model having parameters of $A=2.22 \times 10^{13}, E=154.8 \mathrm{~kJ} / \mathrm{mol}$, and $\mathrm{m}$ and $\mathrm{n} \approx 1$. Even though this activation energy appears to be lower than the mean value of $165 \mathrm{~kJ} / \mathrm{mol}$ for neat HMX, we cannot be sure due to the variability in replicate runs.

Results for the isothermal TGA experiments for CP, HMX, and the CP-HMX are shown in Figure 15. Again, the weight loss of the mixture is clearly that the two materials independently, even though these experiments were conducted in open pans. A quantitative measure of the acceleration is difficult due to changes in character from experiment to experiment of the initial weight loss from neat $\mathrm{CP}$, but generally speaking, the decomposition of the mixture is 3-5 times faster than either HMX along or a weighted average of the two materials independently. This result is qualitatively consistent with the nonisothermal DSC experiments in Figure 14.

The acceleration appears to be greater at the lowest temperature, which supports the concept that the activation energy for decomposition of the mixture is lower than that for HMX alone. Perhaps significant is that Pickard et al. ${ }^{9}$ report an activation energy of $147.3 \mathrm{~kJ} / \mathrm{mol}$ for the endothermic decomposition stage of CP, which is strikingly close to our estimated value for the CP-HMX mixture.

The kinetic results for the CP-HMX mixtures are shown with earlier results for HMX alone in Figure 16. The limited number of kinetic experiments and the variability in the results prevent a quantitative prediction of the mixture reactivity at $100{ }^{\circ} \mathrm{C}$ and below, but one can make a qualitative prediction. First-order kinetic parameters for HMX consistent with the various experiments are $A=2 \times 10^{13} \mathrm{~s}^{-1}$ and $E=165 \mathrm{~kJ} / \mathrm{mol}$. If we assume that the correct activation energy for the mixture is $147 \mathrm{~kJ} / \mathrm{mol}$, the corresponding frequency factor must be $1.2 \times 10^{13} \mathrm{~s}^{-1}$ to have a 6 -fold faster rate constant at $200{ }^{\circ} \mathrm{C}$. When these two rate expressions are extrapolated to $100{ }^{\circ} \mathrm{C}$, one finds that the rate constant for the mixture is 20 times faster than for HMX alone. Consequently, we can conclude that the combination of the faster rate for the CP-HMX mixtures at high temperatures and a lower activation energy result in an extrapolated reactivity that is qualitatively consistent with the enhanced gas generation observed in the Sandia detonator accelerated aging tests.

\section{Short-term Aging Studies of HMX, CP and HMX-CP Mixtures}

Because of the interactions between HMX and CP found for relatively severe thermal exposures in the thermal analysis experiments, additional sealed-tube experiments were conducted for 1 week and 1 month at 100 and $120{ }^{\circ} \mathrm{C}$. This is actually a more severe thermal exposure than a few decades at temperatures between room temperature and $40{ }^{\circ} \mathrm{C}$, as will be discussed. Measurements were made in triplicate, and the average amount of gas generated from HMX-containing experiments in excess of the minor amount from CP alone is given in Table 3. In all cases, the estimated amount of HMX decomposition is less than $0.1 \%$. The amount of HMX decomposition may be as much as two times larger than with HMX alone, but it certainly is not substantially different. 

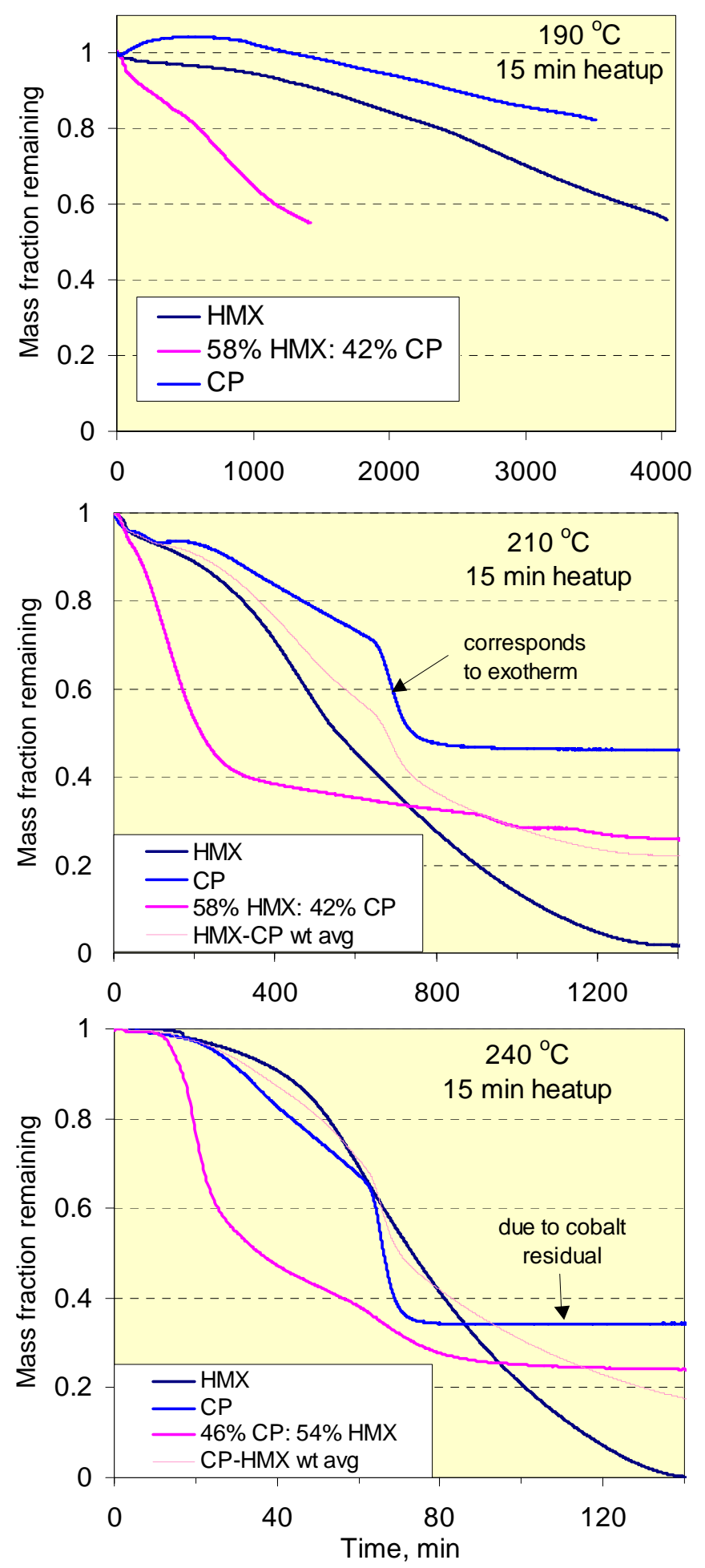

Figure 15. Comparison of isothermal weight loss for neat HMX and CP and mixtures of the two materials. The time for $10 \%$ weight loss is accelerated 3-5 times compared to either HMX alone or a weighted average of the two materials independently. The sharp mass loss for corresponds to a sharp exotherm in the simultaneous delta T signal in the SDT apparatus and probably corresponds to rapid oxidation by perchlorate. 
Table 3. Products from short-term accelerated aging tests in sealed tubes.

\begin{tabular}{|l|c|c|c|c|c|c|}
\hline Materials & $\mathrm{t}(\mathrm{mo})$ & $\mathrm{T}\left({ }^{\circ} \mathrm{C}\right)$ & $\begin{array}{c}\text { Excess } \\
\mathrm{N}_{2}(\mu \mathrm{l})\end{array}$ & $\begin{array}{c}\text { Excess } \\
\mathrm{N}_{2} \mathrm{O}(\mu \mathrm{l})\end{array}$ & $\begin{array}{c}\text { Excess } \\
\mathrm{CO}_{2}(\mu \mathrm{l})\end{array}$ & $\begin{array}{c}\text { \%HMX } \\
\text { decomp }\end{array}$ \\
\hline HMX & 0.23 & 100 & 0.0 & 1.5 & 0.0 & 0.00 \\
\hline HMX & 1.0 & 100 & 0.0 & 5.5 & 1.0 & 0.01 \\
\hline HMX+CP & 0.23 & 100 & 0.0 & 1.0 & 0.0 & 0.00 \\
\hline HMX+CP & 1.0 & 100 & 0.0 & 11 & 1.5 & 0.02 \\
\hline HMX & 0.23 & 120 & 0.0 & 11.5 & 1.0 & 0.02 \\
\hline HMX & 1.0 & 120 & 0.5 & 21.3 & 5.3 & 0.05 \\
\hline HMX+CP & 0.23 & 120 & 0.5 & 9.5 & 0.0 & 0.02 \\
\hline HMX+CP & 1.0 & 120 & 1.5 & 29.3 & 3.3 & 0.07 \\
\hline
\end{tabular}

The obvious question is how these results compare with those in previous sections. The amount of HMX decomposed individually is qualitatively as expected. A simple linear extrapolation of Figure 10 (dividing by two to obtain mass loss) predicts $\sim 0.08 \%$ mass loss for one month and $0.02 \%$ for one week at $120{ }^{\circ} \mathrm{C}$, in excellent agreement with results in Table 3. Similarly, a linear extrapolation of Figure 10 results predicts $0.02 \%$ decomposed for one month at $100{ }^{\circ} \mathrm{C}$, again in excellent agreement with Table 3. The decomposition enhancement of less than two times for HMX-CP mixtures in these experiments might be due to being too early in the autocatalytic interaction. Although both HMX and CP decomposition by themselves are autocatalytic, the detonator results are more strongly autocatalytic than HMX by itself. Consequently, there may be insufficient CP decomposition products at this early stage to have had an acceleratory effect to the extent observed in detonators heated for 50 months at $100{ }^{\circ} \mathrm{C}$.

\section{E. Lifetime Predictions for Storage Conditions}

As mentioned in the introduction, there are two approaches to answering lifetime issues. One is to develop a predictive model for failure as a function of aging, and the second is to expose the components to some presumed equivalent thermal dose and measure the performance degradation either directly or indirectly. Although the model assumptions are less obvious in the second approach, they still do exist in the way the equivalent dose is calculated.

Three issues need to be addressed in either approach: (1) what are the thermal conditions in the storage facility, given that the lifetime will depend on temperature via the Arrhenius equation, (2) how much decomposition is allowed for the component to satisfy performance requirements, and (3) how confident can we be that the mechanism is sufficiently constant that our Arrhenius extrapolation will be valid?

Storage temperatures for explosives would typically be less than $40{ }^{\circ} \mathrm{C}$, and the desired lifetime of the component would be a few decades. The allowable amount of degradation would depend on application, but it is likely in the 1 to $10 \%$ range. Figures 11 and 12 strongly support the validity of an Arrhenius extrapolation. These issues are explored in greater depth in the following paragraphs.

We presented arguments in the HMX kinetics results section that other materials in addition to HMX follow an Arrhenius relationship over many orders of magnitude and that the storage lifetime extrapolation is relatively small compared 


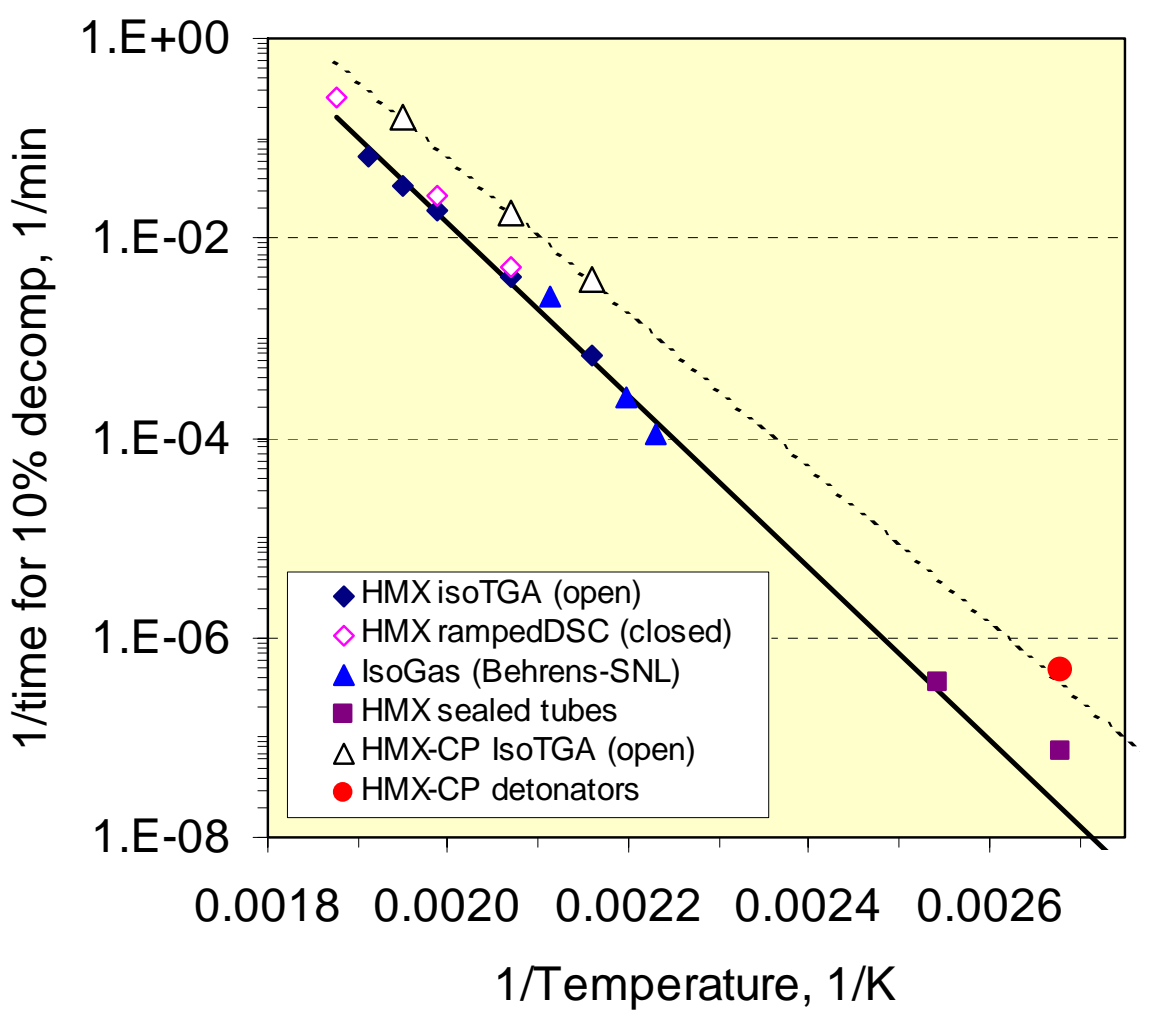

Figure 16. Comparison of the Arrhenius plots for HMX alone, HMX-CP mixtures, and the Sandia aging tests. The enhanced gas yields from the accelerated aging tests are qualitatively consistent with an extrapolation of the high-temperature thermal analysis experiments of CPHMX mixtures.

to the generally accepted Arrhenius extrapolation for petroleum formation. ${ }^{4,5}$ While it is possible that a very low activation energy process such as oxidation or a photolysis might cause a curvature in the Arrhenius plot at low temperatures, this is not likely in a sealed container with no light and minimal oxygen. An enhanced role of hydrolysis reactions due to ambient humidity is more difficult to rule out.

Although the precise lifetime may be difficult to predict, one can establish bounds by approaching the issue from different directions. First, we extend the Arrhenius plot previously shown in Figure 16 to estimate how much time would be required for 1 to $10 \%$ decomposition of the HMX. This extrapolation is shown in Figure 17, and the implications are discussed in following paragraphs. We then estimate the time for the lifetime-equivalent thermal dose in accelerated aging experiment using these activation energies and compare conclusions to the failure extrapolation approach.

The extrapolation based on a combination of the high temperature thermal analysis experiments and the gas yields from the accelerated aging tests predict that $>100,000$ years are needed to attain $10 \%$ HMX decomposition at $30{ }^{\circ} \mathrm{C}$. The extrapolation based on kinetics derived solely from the accelerated aging tests is less favorable due to the lower apparent activation energy. Even so, the mixtures would be expected to survive for $\sim 10,000$ years based on this extrapolation. This estimation does 
not take into account the contribution of possible impurities, which may be responsible for some of the enhanced early decomposition.

Extrapolation to lower amounts of decomposition by a linear model would imply that the lifetime for $1 \%$ allowable decomposition would be 10 times shorter. The most pessimistic estimate from a linear model would be 1000 years. However, two compensating effects complicate the extrapolation. First, there may be a rapid decomposition process that can cause a percent or so decomposition at low thermal stress, and it could be an artifact due to impurities. On the other hand, the main decomposition process is acceleratory, which means that a decrease in the time by a factor of two will cause a reduction in the amount decomposed by more than a factor of two.

The equivalent-lifetime thermal-dose approach comes down clearly on the side that the lifetime of HMX-CP mixtures is much greater than required. Using a conservative value of $150 \mathrm{~kJ} / \mathrm{mol}$ for the activation energy, one finds that 2 days at 100 ${ }^{\circ} \mathrm{C}$ and less than one hour at $120{ }^{\circ} \mathrm{C}$ are equivalent to 50 years at $40{ }^{\circ} \mathrm{C}$. Equivalent times for 30 years at $30{ }^{\circ} \mathrm{C}$ are 10 times less. Consequently, it is clear that the results in Table 3 represent a severe overtest from a strictly thermal degradation standpoint, yet negligible decomposition occurred. As long as the materials are isolated from a continually refreshed source of oxygen or water, other reactions should not be substantially enhanced over those from the sealed-tube result.

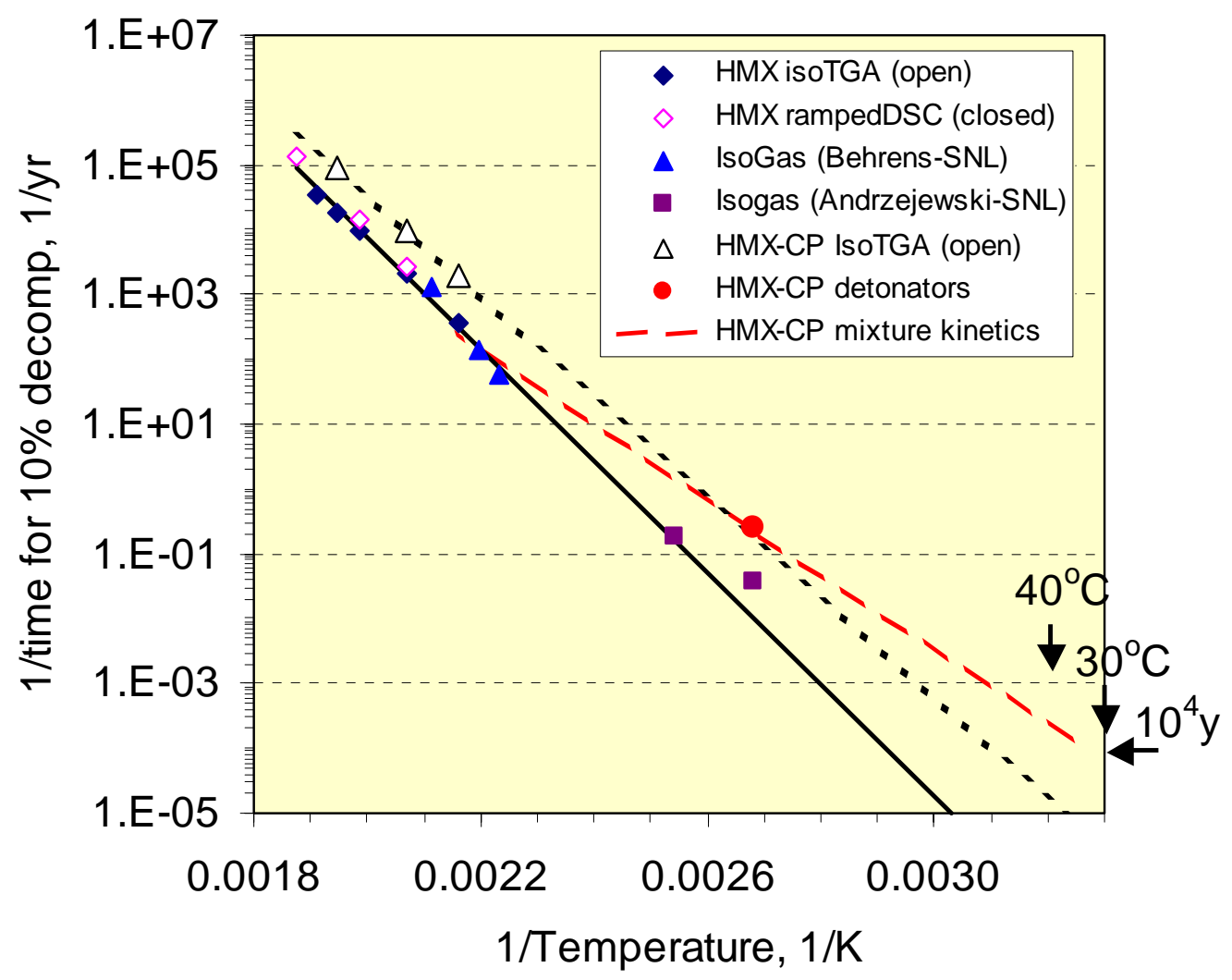

Figure 17. Prediction of mixture lifetimes at $30-40{ }^{\circ} \mathrm{C}$ based on an Arrhenius extrapolation of high-temperature and accelerated aging tests. The predicted lifetimes are much greater than required. 


\section{Conclusions and Recommendations}

Clear evidence for enhanced decomposition of HMX in the presence of CP from both high-temperature thermal-analysis experiments and lower temperature detonator experiments. However, kinetic extrapolations to a hypothetical storage temperature of 30 ${ }^{\circ} \mathrm{C}$ indicates that such mixtures would still last for thousands of years. Although the amount of HMX decomposition that is acceptable depends on application, it is reasonable to use a degradation value between 1 and $10 \%$ in a first-cut assessment. The predicted time for $10 \%$ decomposition is calculated to be from 10,000 to 100,000 years, based on models calibrated on detonator aging tests alone and a combination of the sealed-tube aging and thermal analysis tests. The activation energy from the latter is probably more reliable, giving the longer lifetime prediction.

These long lifetimes must be qualified by the possibility that a low activation energy process related to oxidation or hydrolysis could cause a curvature of the Arrhenius relationship, even though there is substantial evidence in the literature that Arrhenius relationships can persist for $>10$ orders of magnitude differences in reaction rates. However, sealed-tube tests at $120{ }^{\circ} \mathrm{C}$ for a month, which actually represents an overtest of the material by several orders of magnitude, do not show any evidence of substantial reaction. This time is long enough that internal diffusion limitations should be negligible, and enhanced importance of oxidation or hydrolysis reactions could only occur if there were a continuous supply to replace depletion by reaction. Consequently, we consider this mechanistic possibility remote.

\section{Acknowledgments}

We appreciate the support of George Overturf for this work as well as the information provided by Richard Behrens and the helpful review of Leanna Minier.

\section{References}

${ }^{1}$ A. K. Burnham, R. L. Braun, “Global kinetic analysis of complex materials,” Energy \& Fuels 13 (1999) 1.

2 A. K. Burnham, “Application of the Sestak-Berggren equation to organic and inorganic materials of practical interest,” J. Therm. Anal. Cal. 60 (2000) 895.

${ }^{3}$ A. K. Burnham and R. K. Weese, Thermal Decomposition Kinetics of HMX, UCRLTR-204262, May 20, 2004.

${ }^{4}$ R. Behrens and S. Bulusu, "Thermal decomposition of HMX: Low temperature reaction kinetics and their use for assessing response in abnormal thermal environments and implications for long-term aging," in Decomposition, Combustion, and Detonation Chemistry of Energetic Materials, MRS Symp. Proc. 418, T. Brill et al., Eds., Materials Research Society, Pittsburgh, PA.1996, pp. 119-128.

${ }^{5}$ A. K. Burnham, R. H. Sanborn, H. R. Gregg, "Thermal dealkylation of dodecylbenzene and dodecylcyclohexane,” Org. Geochem. 28 (1998) 755-758.

${ }^{6}$ K. J. Jackson, A. K. Burnham, R. L. Braun, K. G. Knauss, "Temperature and pressure dependence of n-hexadecane cracking,” Org. Geochem. 23 (1995) 941-953. 
${ }^{7}$ T. M. Massis, P. K. Morenus, D. H. Huskison, R. M. Merrill, "Stability and compatibility studies with the inorganic explosive 2-(5-cyanotetrazolato) pentaammine cobalt (III) perchlorate,” J. Hazardous Mat. 5 (1982) 309-323.

${ }^{8}$ H. E. Kissinger, Reaction kinetics in differential thermal analysis, Anal. Chem. 29 (1957) 1702-1706.

${ }^{9}$ J. Q. Searcy, K. L. Shanahan, Thermal decomposition of the new explosive 2-(5cyanotetrazolato) pentaamminecobalt(III) perchlorate, SAND78-0466, Sandia National Laboratories, August 1978.

${ }^{10}$ J. M. Pickard, P. S. Back, R. R. Walters, DSC Kinetics of the endothermic solid-state transition of 2-(5-cyanotetrazolato) pentaammine cobalt(III) perchlorate, Report MLM3051, Mound Laboratory, April 15, 1983. 